\title{
Filling an important gap
}

\author{
Alessandra Faggian 1
}

(C) The Japan Section of the Regional Science Association International 2017

The Asia-Pacific Journal of Regional Science is a very welcome addition to the suits of regional science journals available around the world. As one of the editors of Papers in Regional Science (traditionally more centered around Europe) and being on the editorial board of the Journal of Regional Science (born in North America), I have always thought that the Asia-Pacific area needed its own journal. Moreover, over the years, it has become clear to me that the field of regional science has been witnessing a true explosion in the Asia-Pacific area with an increasing number of high-quality contributions originating from there. It was, therefore, time to have a journal specifically targeting this region.

My congratulations and best wishes go to the editors of this new journal in their new endeavor. Creating a new academic journal is never an easy task and requires great passion and determination. Nevertheless, the high caliber of the editors and academics in the editorial board is a guarantee for future success.

Welcome to the regional science journals family!

Alessandra Faggian

NARSC President

Editor Papers in Regional Science

Director of Social Sciences

Alessandra Faggian

alessandra.faggian@gssi.it

1 Gran Sasso Science Institute, L'Aquila, Italy 